\title{
Prevalence and associated factors of undernutrition among adult tuberculosis patients in some selected public health facilities of Addis Ababa, Ethiopia: a cross- sectional study
}

\author{
Berihun Dargie $^{1 *}$, Gezahegn Tesfaye ${ }^{2}$ and Amare Worku ${ }^{3}$
}

\begin{abstract}
Back ground: The prevalence of undernutrition among adult tuberculosis patients is high in developing countries. However it has not been well explored in Ethiopian situation. Therefore the aim of this study was to determine the prevalence of undernutrition and its associated factors among adult TB patients in some selected public health facilities of Addis Ababa.

Methods: An institution based cross-sectional study was conducted. The total sample size of the study was 360. The sample size was allocated to the selected health facilities proportional to their size and study subjects were consecutively enrolled to the study during the study period. Data were collected using a pretested structured questionnaire. The data were entered and cleaned by using EPI info version 3.6.1 and transferred to SPSS version 20 for analysis. Bivariate and multivariate logistic regression analyses were done to identify factors that are associated with undernutrition.

Results: The prevalence of undernutrition was $39.7 \%$ (23.6 \% mild, $8.6 \%$ moderate and $7.2 \%$ severe undernutrition). Functional status of the patients $(A O R=2.57 ; 95 \% \mathrm{Cl}=1.42,4.68)$ and dietary counselling ( $A O R=$ 1.79; $95 \% \mathrm{Cl}=1.03$, 3.12) were factors independently associated with undernutrition among adult TB patients.

Conclusion: The prevalence of undernutrition was found to be very high. Regular nutritional assessment and dietary counselling should be part of the routine care of adult TB patients.
\end{abstract}

Keywords: Prevalence, Undernutrition, TB, Health facilities

\section{Background}

Malnutrition is a broad term which refers to both undernutrition and over nutrition [1]. Individuals are undernourished if their diet does not provide them with adequate calories and protein for maintenance as well as growth or if they cannot fully utilize the food they eat due to illness [2]. Even if people get enough to eat, they will become undernourished if the food they eat does

\footnotetext{
* Correspondence: berihun_dargie@yahoo.com

${ }^{1}$ Kasanchis Health Center, Disease prevention and control department, TB

clinic, Addis Ababa, Ethiopia

Full list of author information is available at the end of the article
}

not supply the proper amounts of micronutrients to meet daily nutritional requirements [3].

There are a number of adult tuberculosis (TB) patients suffering from profound undernutrition in the world especially in developing countries [3, 4]. It is estimated that undernutrition causes about one quarter of all new TB cases globally [5]. This can have serious public health impacts if those with undernourished adult TB are not identified early [6]. The relationship between undernutrition and active tuberculosis infection is bidirectional. Having active tuberculosis leads to loss of weight, and being underweight is known risk factor for developing tuberculosis either through the reactivation of latent 
tuberculosis or the development of progressive primary disease upon infection [7].

Tuberculosis is associated with various socioeconomic factors such as poverty [8], poor housing $[9,10]$ and economic deprivation $[11,12]$ which lead to poor nutritional status and impaired immune function [10-12]. Nutrition is important for health and functioning of all systems of the body including the immune system. This is because malnutrition weakens the immune system and thus the ability of the individual to fight infection like TB and their ability to control disease progression will be compromised [6]. Among the known risk factors for active tuberculosis (undernutrition, HIV infection, diabetes, cancer), undernutrition has the highest population attributable fraction of $27 \%$ [7].

Understanding the magnitude of undernutrition and its associated factors among adult TB patients is crucial in designing appropriate interventions to address the nutritional problems of adult TB patients [13, 14]. However, despite the high burden of TB and undernutrition in Ethiopia only few studies have been conducted regarding the prevalence and associated factors of undernutrition among adult TB patients in Ethiopia. A study conducted at Yirgalem hospital in Sidama [15] found a high prevalence of undernutrition (77.9\%), though this study was mainly focused on the effect of malnutrition on the outcome of tuberculosis. Another study in Gondar (16) also showed a higher magnitude of undernutriiton (65.4\%), however this study was primarily investigated the general serum level of micronutrient among TB patients. Moreover, these studies were limited to few health facilities, were undertaken at hospital level, did not solely address the issue of undernutrition in adult TB patients and were conducted long ago. Hence, this study was planned to particularly assess the prevalence of undernutrition and its associated factors among TB patients in some selected public health facilities of Addis Ababa, Ethiopia.

\section{Methods}

\section{Study design and setting}

An institution based cross-sectional study was conducted. The study was conducted at Addis Ababa, the capital city of Ethiopia. According to the central statistical agency of Ethiopia, the city has an estimated total population of $3,103,999$, out of which $1,479,000$ were men and 1,624,999 women in 2012. In Addis Ababa there are ten sub-cities and 99 kebeles (the lowest administrative unit in Ethiopia). In the city there are 80 public health facilities, of which 14 are hospitals and the remaining 66 are health centers. Each health center has a catchment population of 40,000. There are also 35 private and 3 Non-Governmental Organizations (NGOs) hospitals in the city. The study was conducted from November 2013 to January 2014.

\section{Source and study population}

The source populations were TB patients who have follow up at public health facilities of Addis Ababa. Whereas the study populations were TB patients aged 18 years and above who have follow up at TB clinics of the selected public health facilities. TB patients who were 18 years and above, came to attend their follow up during the first two months of treatment and volunteers to participate were included in the study. All TB patients who cannot properly communicate, are mentally ill, have physical disabilities, and are pregnant or lactating mothers (Body Mass Index (BMI) was difficult to assess) were excluded from the study.

\section{Study variables}

The outcome variable was undernutrition. Adult TB patients with BMI $<18.5 \mathrm{Kg} / \mathrm{m}^{2}$ were considered to have undernutrition. BMI was calculated after measuring weight and height. In order to measure weight, the patient should remove shoes, in minimal clothing, standing erect on the center of the balance and record the weight to the nearest 0.1 kilo gram. By the same procedure the height was measured by asking the patient to be barefoot, wearing no head gear, knees were fully straight and both hands were held down to the side and record the height to the nearest 0.5 centimeter. The predictor variables were socio-demographic variables, eating problem, HIV status, dietary counselling, house hold hunger scale and participation in nutrition intervention.

\section{Sample size determination}

The sample size was determined considering the following assumptions using the single population formula. $\mathrm{Z}$ score at $95 \% \mathrm{CI}=1.96$, margin of error $=4 \%$, the prevalence of undernutrition among TB patients in Gondar $65.4 \%$ [16] giving a sample size of 550. Since the numbers (470) of TB patient who have follow up at public health facilities in the study area were less than 10,000 we used correction formula which yields a sample size of 253. Then adding a $10 \%$ non-response rate, the sample size became 278. A study conducted in Ghana [13] found income, educational status and family size to be factors associated with undernutrition among TB patients. By taking these factors into consideration, $95 \%$ confidence interval, $10 \%$ non-response rate, exposed to non-exposed ratio of $1: 2$ and taking $80 \%$ power give the following results. Income (undernutrition among exposed $57 \%$ and unexposed $43 \%$ gives a sample size of 356), educational status (undernutrition among exposed $66 \%$ and unexposed $44 \%$ yields a sample size of 360) and family size (undernutrition in exposed $53 \%$ and unexposed $47 \%$ gives a sample size of 360). From the above calculation the minimum larger sample size was 360 which is the final sample size of this study. 


\section{Sampling procedure}

In Addis Ababa there are ten sub-city health bureaus; from each sub-city one health center which renders anti-TB service was randomly selected based on the recent two months TB patient flow. Then the total sample size was proportionally allocated to the number of adult TB patients at each health center and participants were interviewed consecutively (Fig. 1). In order to avoid double counting those TB patients coming for follow up were asked if they were interviewed for this study in previous days and excluded from the interview if they had been.

\section{Data collection tools, procedure and quality assurance}

A pretested and structured questionnaire was used for the study (Additional file 1). After pretesting, some unclear or vague questions were modified and wrong skip patterns were also corrected. The questionnaire was prepared first in English and translated to Amharic (the official language of Ethiopia) then back to English so as to check for consistency. The data was collected by trained health professionals who have a previous basic knowledge of TB and those who are working in the TB clinic. Data collectors were provided with two days training on the objective, methods, tool and ethics of the study. The data collection process was supervised by two health officers and the principal investigator on a daily basis.

\section{Data analysis and management}

First, each questionnaire was cleaned and checked for completeness. Then the data were entered to EPI info version 3.6.1 computer software. Thereafter the data were exported to SPSS windows version 20 for analysis. Frequency, percentage and mean were run to get descriptive statistics of the data. Bivariate logistic regression analysis was done to explore the crude association between different predictor variables and undernutrition. To control for possible confounding factors and to identify factors that are independently associated with undernutrition, multivariate logistic regression analysis was performed for those variables with $p$ value of less than 0.2 in the bivariate analysis. Having a $\mathrm{p}$ value less than 0.05 was used to declare the presence of statistically significant association between different variables.

\section{Operational definitions \\ Body mass index (BMI)}

Is defined as the weight in kilogram of the individual divided by the square of the height in meter and used to determine the nutritional status of TB patients and classified as follows: Severe undernutrition $\left(\mathrm{BMI}<16.0 \mathrm{Kg} / \mathrm{m}^{2}\right)$, moderate undernutrition $\left(\mathrm{BMI}=16.0-16.99 \mathrm{Kg} / \mathrm{m}^{2}\right)$, mild undernutrition $\left(\mathrm{BMI}=17.0-18.49 \mathrm{Kg} / \mathrm{m}^{2}\right)$, normal weight $\left(\mathrm{BMI}=18.5-24.99 \mathrm{Kg} / \mathrm{m}^{2}\right)$, over weight $(\mathrm{BMI}=25.0-29.99$

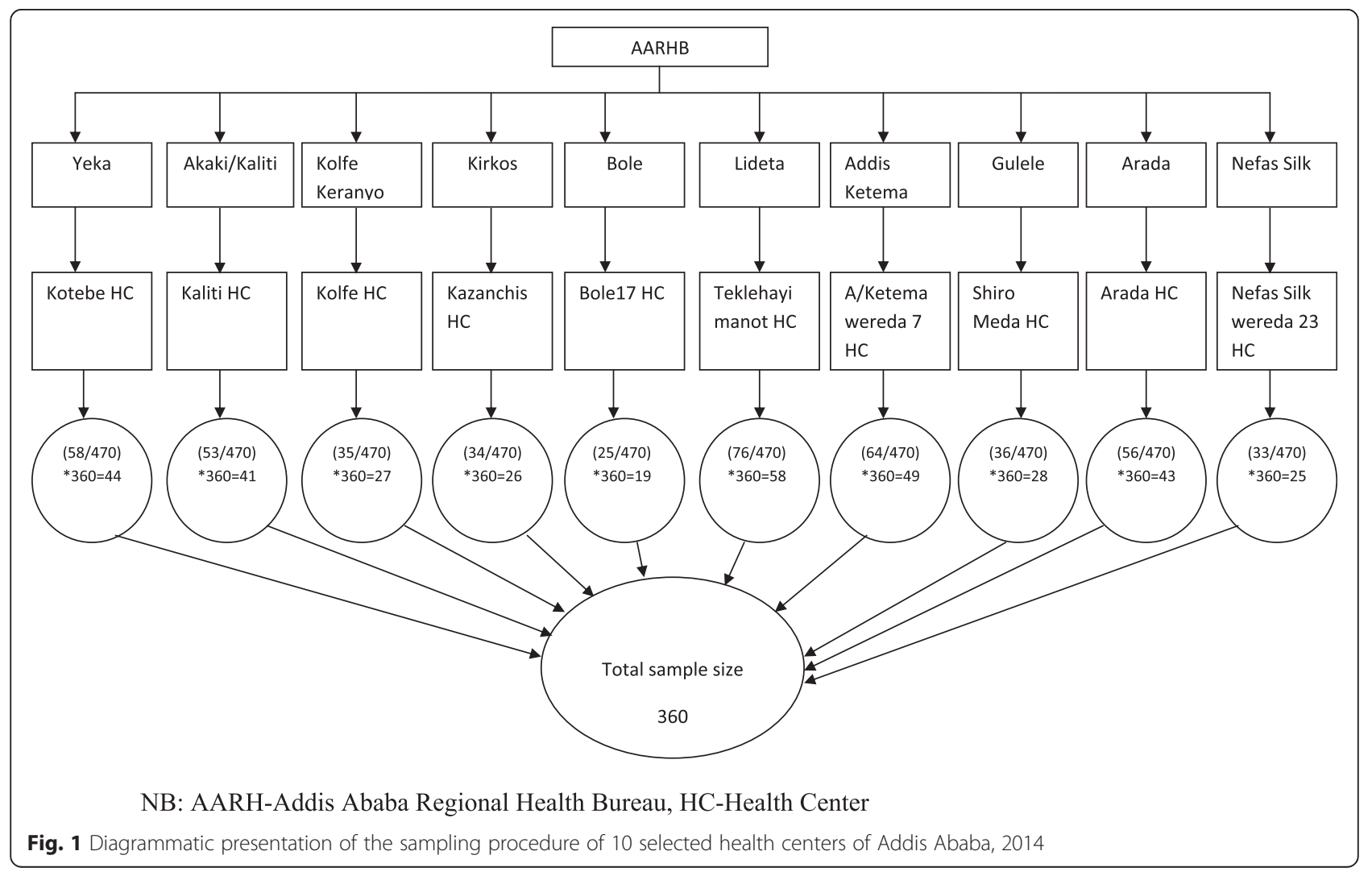


$\mathrm{Kg} / \mathrm{m}^{2}$ ) and obesity (BMI $\geq 30.0 \mathrm{Kg} / \mathrm{m}^{2}$ ) (Source: WHO $1995,2000 \& 2004)$.

\section{Household Hunger Scale (HHS)}

Is a household food deprivation scale derived from the United States (U.S) household food security survey module for use in developing country contexts and to assess the validity of the Household Food Insecurity Access Scale (HFIAS) for cross-cultural use. HHS has three house hold hunger categories as follows: HHS of 0-1 (little or no hunger), HHS of 2-3 (moderate hunger), HHS of 4-6 (severe hunger) in the house hold. (Source: Food and Nutrition Technical Assistance III Project (FANTA), 2011).

\section{Dietary counselling}

Is a process by which a health professional with special training in nutrition helps people make healthy food choices and form healthy eating habits.

\section{Functional status}

$\checkmark$ Working: Able to carry on normal activity and no special care needed.

$\checkmark$ Ambulatory: Unable to work, able to live at home and able to care for most of personal needs and requires occasional assistance.

$\checkmark$ Bed ridden: Unable to care for self, require institutional or hospital care

\section{Nutritional care and support}

Have many components such as nutrition education and counselling in health facilities, water, hygiene or food safety interventions to prevent diarrhea as well as provision of adequate quality/quantity of food and food aid by any organization.

\section{Ethical consideration}

The study protocol was reviewed and ethical clearance was obtained from Institutional Review Board of university of Gondar and Addis Ababa city administration health bureau. A formal letter of permission was sent to the respective health centers. The participant's confidentiality was assured by avoiding their name and other personal identifying information. Participants were assured that their decision not to participate wouldn't hamper their follow up care at the health facility and they can discontinue from participating in the research at any time. The interview took place after informed written consent was obtained from each participant.

\section{Results}

Socio-demographic characteristics

A total of 360 adult TB patients were involved in the study making the response rate $100 \%$. The mean age of the study participants was $33.6( \pm \mathrm{SD}=12.7)$ years with a minimum age of 18 years and maximum age of 85 years. The majority of the respondents were male 201(55.8\%), Amhara 165(45.8 \%), married 155(43.1\%), in secondary school education 113(31.4\%), merchants/self-employed $122(33.9 \%)$ and have a family size less than or equal to four 255 (70.8\%). The average income of a house hold in this study was 1077 Ethiopian Birr (Table 1).

\section{Nutritional intervention history and household hunger scale}

Of the 360 respondents, 212 (58.9\%) did not get dietary counselling by their treating clinicians and only 13 (3.6\%) of respondents received nutritional support from any organization. The majority of respondents 310 (86.1\%) consumed three meals or more per day and 348 (96.7\%) and have little or no hunger based on their household hunger score (Table 2).

\section{Nutritional status of adult TB patients}

In this study, the prevalence of undernutrition was found to be $39.7 \%$, of this $23.6 \%$ have mild, $8.6 \%$ moderate and $7.2 \%$ severe undernutrition. Furthermore, greater than half of the respondents 193 (53.6\%) had normal weight based on BMI classification (Fig. 2).

\section{Health status of adult TB patients}

Most of the respondents 324(90\%) had awareness about TB. Among the study participants, 259(71.9\%) had pulmonary tuberculosis and 232(64.4\%) were on anti-TB treatment for less than or equal to four weeks. More than half of the respondents 215(58.9\%) were ambulatory by their functional status. Of all participants in this study 59(16.4\%) had eating problem and 80(22.2\%) stated that they felt sadness or depression. Among the participants, $89(24.7 \%)$ of them have had chronic illness, of which 74(83.1\%) were HIV positive (Table 3).

\section{Factors associated with undernutrition in adult TB patients}

In the bivariate analysis different variables were found to be significantly associated with undernutrition. These include functional status (ambulatory $(C O R=$ 2.14; $95 \% \mathrm{CI}=1.36,3.36)$ and bed ridden $(\mathrm{COR}=$ 9.95; $95 \% \mathrm{CI}=1.08,91.72)$ ), received dietary counselling $(\mathrm{COR}=1.71 ; 95 \% \mathrm{CI}=1.11,2.63)$, being $\mathrm{HIV}$ positive $(\mathrm{COR}=1.70,95 \% \mathrm{CI}=1.02,2.84)$ and eating problem $(\mathrm{COR}=1.87,95 \% \mathrm{CI}=1.07,3.28)$ with $\mathrm{p}$ value of less than 0.05 . In the bivariate analysis, undernutrition has no significant association with age, 
Table 1 Socio-demographic characteristics of adult TB patients in some selected public health facilities of Addis Ababa, Ethiopia, 2014

\begin{tabular}{|c|c|c|}
\hline Variable & Number & Percent \\
\hline \multicolumn{3}{|l|}{$\operatorname{Age}(N=360)$} \\
\hline$<24$ & 90 & 25 \\
\hline $24-30$ & 94 & 26.1 \\
\hline $31-40$ & 87 & 24.2 \\
\hline$>40$ & 89 & 24.7 \\
\hline \multicolumn{3}{|l|}{ Sex } \\
\hline Male & 201 & 55.8 \\
\hline Female & 159 & 44.2 \\
\hline \multicolumn{3}{|l|}{ Ethnicity } \\
\hline Amhara & 165 & 45.8 \\
\hline Tigre & 34 & 9.4 \\
\hline Oromo & 76 & 21.1 \\
\hline Guraghe & 66 & 18.3 \\
\hline Other & 19 & 5.3 \\
\hline \multicolumn{3}{|l|}{ Marital Status } \\
\hline Married & 155 & 43.1 \\
\hline Unmarried & 154 & 42.8 \\
\hline Divorced/separated & 24 & 6.7 \\
\hline Widowed & 27 & 7.5 \\
\hline \multicolumn{3}{|l|}{ Educational Status } \\
\hline Illiterate/ read and write & 83 & 23.1 \\
\hline Primary school & 98 & 27.2 \\
\hline Secondary school & 113 & 31.4 \\
\hline Tertiary education & 66 & 18.3 \\
\hline \multicolumn{3}{|l|}{ Occupational Status } \\
\hline Employed(Gov, NGO) & 83 & 23.1 \\
\hline Merchant /self-employed & 122 & 33.9 \\
\hline Daily Laborers/house made & 53 & 14.7 \\
\hline Unemployed (student, housemaid) & 102 & 28.3 \\
\hline \multicolumn{3}{|l|}{ Monthly income $(N=256)$} \\
\hline$<=800$ ETB & 77 & 21.4 \\
\hline 800-1500 ETB & 86 & 24.4 \\
\hline$>=1500 \mathrm{ETB}$ & 130 & 25.3 \\
\hline \multicolumn{3}{|l|}{ Family Size } \\
\hline$<=$ Four & 255 & 70.8 \\
\hline$>$ Four & 105 & 29.2 \\
\hline
\end{tabular}

sex, marital status, occupational status, educational status, duration on anti-TB treatment, family size, income, type of $\mathrm{TB}$, nutritional support and eating frequency. The following variables with a p-value less than 0.2 were taken to the final model for multivariate analysis: age, occupational status, functional status, TB/HIV co-infection, dietary counselling, eating
Table 2 Nutritional Intervention History and Household Hunger scale of adult TB patients in some selected public health facilities of Addis Ababa, 2014

\begin{tabular}{lll}
\hline Variables & Number & Percent \\
\hline Eating frequency $<=2$ & 36 & 10.0 \\
$>=3$ & 310 & 86.1 \\
No specific meal time & 14 & 3.9 \\
Nutritional care and support & & \\
Yes & 13 & 3.6 \\
No & 347 & 96.4 \\
Received dietary counseling & & \\
Yes & 148 & 41.1 \\
No & 212 & 58.9 \\
Household Hunger Score & & \\
0-1(Little or No hunger) & 348 & 96.7 \\
2-3(Moderate hunger) & 11 & 3.1 \\
4-6(Severe hunger) & 1 & 0.3 \\
\hline
\end{tabular}

problem, type of $\mathrm{TB}$ and income. After controlling the other variables, only functional status and dietary counselling remained significantly associated with undernutrition. Patients with ambulatory functional status were 2.6 times more likely to develop undernutrition compared to those who have working functional status $(\mathrm{AOR}=2.57 ; 95 \% \mathrm{CI}=1.42,4.68)$. Patients who had not received dietary counselling were 1.8 times more likely to be undernourished compared with those who had received dietary counselling ( $\mathrm{AOR}=1.79 ; 95 \% \mathrm{CI}=1.03,3.12)$ (Table 4).

\section{Discussion}

This study demonstrated that more than one third of adult TB patients were undernourished. Moreover, functional status of the patients and receiving dietary counselling were factors significantly associated with undernutrition among adult TB patients.

In this study, the prevalence of undernutrition among adult TB patients was (39.7\%) which is higher than a study conducted in Peru (21\%) [13] but it is lower when compared with another study done in Gulbarga, India (62.2\%) [17]. The difference in results between these two studies may be due to the socio-economic difference between the two countries and the study in India used a different method of data collection. In other African countries the prevalence of undernutrition among $\mathrm{TB}$ patients is also high. A study in Ghana [18] revealed that the prevalence of undernutrition among $\mathrm{TB}$ patients to be $51 \%$, which is higher than the findings of this study. This might be due to the fact that the study in Ghana was conducted among patients who have been followed in hospital level where they are expected to 


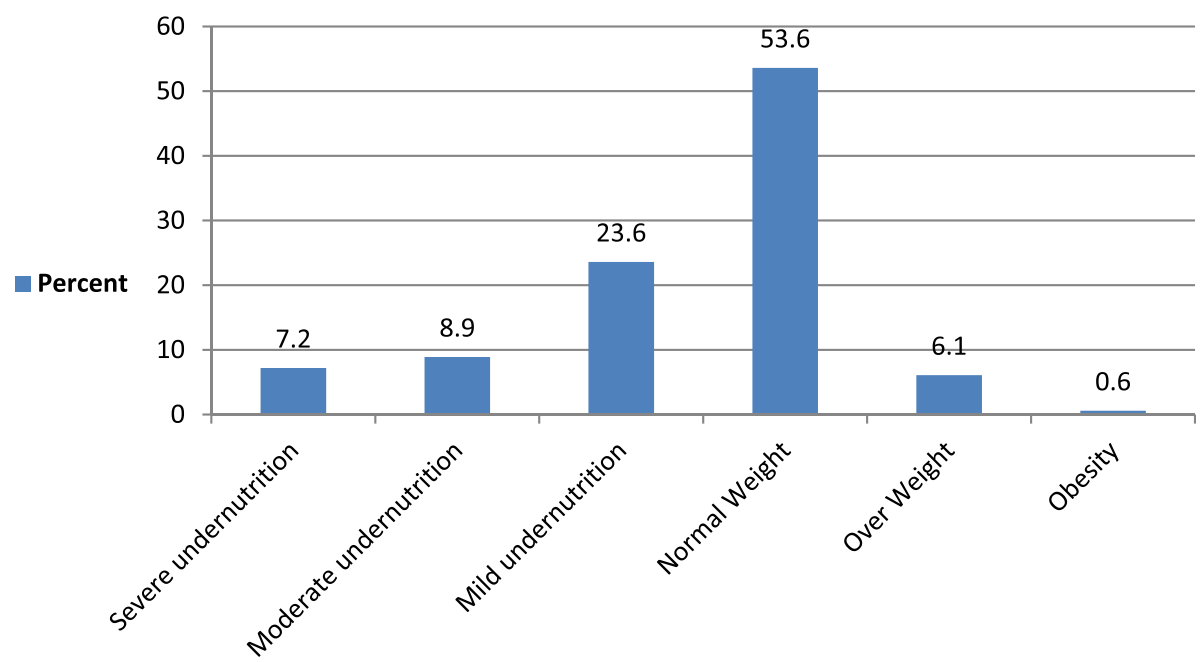

Fig. 2 Nutritional status of adult TB patients in some selected public health facilities of Addis Ababa, Ethiopia 2014

Table 3 Health status of adult TB patients in some selected public health facilities of Addis Ababa, 2014

\begin{tabular}{|c|c|c|}
\hline Variables & Frequency & Percent \\
\hline \multicolumn{3}{|l|}{ Ever heard of TB } \\
\hline Yes & 324 & 90 \\
\hline No & 36 & 10 \\
\hline \multicolumn{3}{|l|}{ Types of TB } \\
\hline Pulmonary TB & 259 & 71.9 \\
\hline Extra pulmonary TB & 101 & 28.1 \\
\hline \multicolumn{3}{|l|}{ Duration on anti TB } \\
\hline$<=4$ weeks & 232 & 64.4 \\
\hline 5-8 Weeks & 128 & 35.6 \\
\hline \multicolumn{3}{|l|}{ Functional Status } \\
\hline Working & 143 & 39.7 \\
\hline Ambulatory & 215 & 58.9 \\
\hline Bed ridden & 5 & 1.4 \\
\hline \multicolumn{3}{|l|}{ Eating Problem } \\
\hline Yes & 59 & 16.4 \\
\hline No & 301 & 83.6 \\
\hline \multicolumn{3}{|l|}{ Feel sad or depressed } \\
\hline Yes & 80 & 22.2 \\
\hline No & 280 & 77.8 \\
\hline \multicolumn{3}{|l|}{ Chronic illness $(N=91)$} \\
\hline HIV/AIDS & 74 & 83.1 \\
\hline Diabetes & 10 & 11.2 \\
\hline Hypertension & 6 & 6.7 \\
\hline Cancer & 1 & 1.1 \\
\hline \multicolumn{3}{|l|}{ HIV/AIDS } \\
\hline Yes & 74 & 20.6 \\
\hline No & 286 & 79.4 \\
\hline
\end{tabular}

be undernourished. Moreover, the BMI of the participants was taken at the time of diagnosis before starting anti-TB medications when patients have not recovered from their illness and were at the state of critical undernourishment which could overestimate the expected figure. A study conducted in other African countries such as Malawi $57 \%$ and Uganda $62 \%$ also found a high prevalence $[6,19]$. This higher prevalence of undernutrition in those studies compared to the current study could be attributed to the difference in socio-cultural situation, life style, feeding pattern and economic status of the countries. Other Ethiopian based studies have also shown a higher result. A study conducted in Gondar, $65.4 \%$ [16] and Sidama, $77.9 \%$ [15] revealed higher prevalence of undernutrition among adult tuberculosis patients compared to this study. This may be attributed to the difference in study context (urban dweller TB patients) and in socio-economic status of the society in those areas. Besides, those studies were conducted a long time ago when the economic status of the country was relatively low which had an impact on the nutritional status of the society in general TB patients in particular.

Many patients with TB in Ethiopia have low functional status when first seen at TB treatment unit. Functional status of the patients is usually related with their underlying medical condition in which patients with deteriorated functional status could have a compromised health status. This condition may result in reduced intake of food which may in turn result in undernutrition [15]. This fact is in line with the findings of this study in which those patients with ambulatory functional status were more likely to be undernourished compared to those who had working functional status. 
Table 4 Bivariate and multivariate analysis on factors associated with undernutrition among adult TB patients in some selected public health facilities of Addis Ababa, 2014

\begin{tabular}{|c|c|c|c|c|c|c|}
\hline \multirow[t]{2}{*}{ Variables } & \multicolumn{2}{|c|}{ Undernutrition } & \multirow[t]{2}{*}{ COR(95 \% Cl) } & \multirow[t]{2}{*}{$P$ value } & \multirow[t]{2}{*}{$\mathrm{AOR}(95 \% \mathrm{Cl})$} & \multirow[t]{2}{*}{$P$ value } \\
\hline & Yes (\%) & No (\%) & & & & \\
\hline \multicolumn{7}{|l|}{ Age } \\
\hline$<24$ & $42(29.4)$ & $48(22.1)$ & 1.00 & & 1.00 & \\
\hline $24-30$ & $31(21.7)$ & 63(29.0) & $0.56(0.31,1.02)$ & 0.059 & $0.58(0.26,1.30)$ & 0.187 \\
\hline $31-40$ & $34(23.8)$ & $53(24.4)$ & $0.73(0.40,1.33)$ & 0.309 & $0.84(0.39,1.81)$ & 0.661 \\
\hline$>40$ & $36(25.2)$ & $53(24.4)$ & $0.78(0.43,1.40)$ & 0.402 & $0.55(0.25,1.23)$ & 0.146 \\
\hline \multicolumn{7}{|l|}{ Occupational status } \\
\hline Employed(Government \& NGO) & $37(25.9)$ & $46(21.2)$ & 1.00 & & 1.00 & \\
\hline Merchant /Self -Employed & $40(28.0)$ & $82(37.8)$ & $0.61(0.34,1.08)$ & 0.088 & $0.64(0.33,1.25)$ & 0.188 \\
\hline Daily laborer/house made & $21(14.7)$ & $32(14.7)$ & $0.82(0.41,1.64)$ & 0.569 & $0.63(0.26,1.56)$ & 0.319 \\
\hline Unemployed (house wife, Student) & $45(31.5)$ & $57(26.3)$ & $0.98(0.55,1.76)$ & 0.950 & $0.76(0.33,1.76)$ & 0.518 \\
\hline \multicolumn{7}{|l|}{ Functional Status } \\
\hline Working & $41(28.7)$ & $102(47.0)$ & 1.00 & & 1.00 & \\
\hline Ambulatory & $98(68.5)$ & $114(52.5)$ & $2.14(1.36,3.36)$ & 0.001 & $2.57(1.42,4.68)$ & 0.002 \\
\hline Bed ridden & $4(2.8)$ & $1(0.5)$ & $9.95(1.08,91.72)$ & 0.043 & $2.34(0.16,33.82)$ & 0.532 \\
\hline \multicolumn{7}{|l|}{ TB/HIV co-infection } \\
\hline Yes & $37(25.9)$ & $37(17.1)$ & 1.00 & & 1.00 & \\
\hline No & 106(74.1) & 180(82.9) & $1.70(1.02,2.84)$ & 0.044 & $1.28(0.66,2.52)$ & 0.466 \\
\hline \multicolumn{7}{|l|}{ Dietary Counseling } \\
\hline Yes & $70(49.0)$ & $78(35.9)$ & 1.00 & & 1.00 & \\
\hline No & $73(51.0)$ & 139(64.1) & $1.71(1.11,2.63)$ & 0.014 & $1.79(1.03,3.12)$ & 0.039 \\
\hline \multicolumn{7}{|l|}{ Eating Problem } \\
\hline Yes & $31(21.7)$ & $28(12.9)$ & 1.00 & & 1.00 & \\
\hline No & $112(78.3)$ & 189(87.1) & $1.87(1.07,3.28)$ & 0.029 & $1.75(0.85,3.62)$ & 0.129 \\
\hline \multicolumn{7}{|l|}{ Type of TB } \\
\hline Pulmonary TB & 109(76.2) & $150(69.1)$ & 1.00 & & 1.00 & \\
\hline Extra pulmonary TB & $34(23.8)$ & $67(30.9)$ & $0.70(0.43,1.13)$ & 0.143 & $0.77(0.41,1.45)$ & 0.420 \\
\hline \multicolumn{7}{|l|}{ Income(N = 256) } \\
\hline$<800$ ETB & $38(36.5)$ & $39(25.7)$ & 1.00 & & 1.00 & \\
\hline 800-1500 ETB & $34(32.7)$ & $54(35.5)$ & $0.65(0.35,1.20)$ & 0.167 & $0.61(0.31,1.19)$ & 0.061 \\
\hline$>1500$ ETB & $32(30.8)$ & 59(38.8) & $0.56(0.30,1.04)$ & 0.064 & $0.51(0.25,1.03)$ & 0.593 \\
\hline
\end{tabular}

In this study patients who did not receive dietary counselling were more likely to be undernourished compared with those who received dietary counselling. This might be because those TB patients who have received dietary counselling became more knowledgeable about the dietary issues and they might appropriately apply the advices to take adequate quantity and quality of variety of foods. Due to this reason those patients who received dietary counselling tend to be well nourished.

Even though TB and HIV infections are both independently associated with undernutrition, co infection with HIV may exacerbate the extent of undernutrition
[7]. A study in Gondar showed that the prevalence of undernutrition in adult TB patients co-infected with HIV was $71.6 \%$, which is higher when compared with the finding of this study $25.9 \%$. This could be due to the fact that the study in Gondar has included high number of TB/HIV co-infected patients who were more exposed to undernutrition because of double burden [16].

A study conducted in Ghana [18] showed that income, educational status and family size were factors associated with undernutrition. However, in this study these factors were not found to be associated with undernutrition. 
This could be due to the relatively smaller sample size of this study that may not be powered to detect the difference.

Tuberculosis was associated with feeding problems which directly affects the amount of food intake by the patient. Some studies $[8,20]$ revealed that eating problem mainly loss of appetite, nausea and vomiting had significant association with undernutrition. However the finding of this study was inconsistent with the above studies, which might be due to the difference in duration since on anti-tuberculosis, because this study has only involved TB patients who were taking medications up to two months which was the expected time for the patients to start recovering from the disease in whom there is less episodes of loss of appetite, nausea and vomiting.

\section{Strengths and limitations of the study}

The study has addressed an important area of research which could be an input for prevention of health problems related to undernutrition in adult TB patients and the study has high response rate. Besides, use of BMI machines to determine undernutrition made the data more reliable. This study has also some limitations; the study may not be generalized to other parts of country because of the difference in socio-demographics and economic situations as well as the inclusion of health centers only. Additionally, there is lack of data on undernutrition in comparable groups of adult patients without TB infection.

\section{Conclusions}

The prevalence of undernutrition among adult TB patients was very high with the majority having a mild form. Functional status of the patient and receiving dietary counselling were factors independently associated with undernutrition in adult TB patients. Regular nutritional assessment and dietary counselling of all TB patients should be the part of routine care for TB patients. Interventions by different stake holders should be targeted based on the patient's nutritional status. TB care providers should receive training which focus on dietary counselling for TB patients.

\section{Additional files}

Additional file 1: English version of the questionnaire. (DOCX $24 \mathrm{~kb}$ )

\section{Competing interests}

The authors would like to declare that they have no competing interest.

\section{Authors' contributions}

$\mathrm{BD}$ has conceived of the study, carried out the overall design and execution of the study, performed data collection and statistical analysis. GT has participated in data analysis, revised the paper for intellectual content and has drafted the manuscript. AW has critically revised the design of the study, data collection techniques and worked out statistical analysis. All authors read and finally approved this manuscript for submission.

\section{Acknowledgment}

We would like to sincerely thank data collectors, supervisors and study participants who took part in this study. Our heartfelt gratitude also goes to those individuals who are directly or indirectly contributed for the realization of this study. We would like to thank Addis Continental Institute of Public Health for their financial support to this study.

\section{Author details}

${ }^{1}$ Kasanchis Health Center, Disease prevention and control department, TB clinic, Addis Ababa, Ethiopia . ${ }^{2}$ Department of public health, Haramaya University, College of health and medical sciences, Harar, Ethiopia.

${ }^{3}$ Department of Nutrition, Addis Continental Institute of public Health, Addis Ababa, Ethiopia.

Received: 4 May 2015 Accepted: 19 January 2016

Published online: 27 January 2016

\section{References}

1. USAID, IASC. Harmonized training manual, introduction to nutrition and emergency. 2011.

2. Federal Democratic Republic of Ethiopia. Ethiopian Guide to Clinical Nutrition Care for Children and Adults with HIV. 2010.

3. NICUS. Tuberculosis and Malnutrition in South Africa. 2007. http://www.sun. ac.za/english/faculty/healthsciences/nicus/Documents/Files/Files/Fact_ sheets/TB\%20and\%20Nutrition.pdf.

4. WHO. Nutritional care and support for patients with tuberculosis. 2013.

5. Federal Ministry of Health (FMOH). Participant manual for the Basic Chronic HIV Care, Antiretroviral Therapy and Prevention in Ethiopia. 2008.

6. Zachariah R, Spielmann MP, Harries AD, Salaniponi FML. Moderate to severe malnutrition in patients with tuberculosis is a risk factor associated with early death. Trans R Soc Trop Med Hyg. 2002;96:291-4.

7. Semba RD, Hill ID, Pee SD. Addressing tuberculosis in the context of malnutrition and HIV co-infection. Food Nutr Bull. 2010;31(4):S345-64.

8. Leung CC, Yew WW, Tam CM, Chan CK, Chang KC, Law WS, et al. Socioeconomic factors and tuberculosis: a district-based ecological analysis in Hong Kong. Int J Tuberc Lung Dis. 2004;8(8):958-64.

9. Dheeraj G, Kshaunish D, Balamughesh T, Ashutosh N, Surinder K. The role of socio-economic factors in tuberculosis prevalence. Indian J Tuberc. 2004;51:27-31.

10. Kennedy N, Ramsay A, Uiso L, Gutmann J, Ngowi Fl, Gillespie SH. Nutritional status and weight gain patients with pulmonary tuberculosis in Tanzania. Trans R Soc Trop Med Hyg. 1996;90:162-6.

11. Van Lettow M, Harries AD, Kumwenda JJ, Zijlstra EE, Clark TD, Taha TE, et al. Micronutrient malnutrition and wasting in adults with pulmonary tuberculosiswith and without HIV co-infection in Malawi. BMC Infect Dis. 2004;4(61):1-8.

12. Harries AD, Nkhoma WA, Thompson PJ, Nyangulu DS, Wirima JJ. Nutritional status in Malawian patients with pulmonary tuberculosis and response to chemotherapy. Eur J Clin utr. 1988;42:445-50.

13. Krapp F, Veliz JC, Cornejo E, Gotuzzo E, Seas C. Bodyweight gain to predict treatment outcome in patients with pulmonary tuberculosis in Peru. Int J Tuberc Lung Dis. 2008;12(10):1153-9.

14. Ezekiel Mupere MBCB,MMED,MS, Zalwango S, Chiunda A, Okwera A, Mugerwa R, MMED, Whalen C. Body Composition among HIV Sero-positive and HIV-sero-negative adult patients with Pulmonary Tuberculosis in Uganda. Ann Epidemiol. 2010;20(3):210-6.

15. Madebo T, Bernt L. The impact of Functional Performance, HIV status, malnutrition, and Clinical features on treatment outcomes of patients with Pulmonary Tuberculosis, Sidama, Ethiopia. Ethiop J Health Dev. 2000;14(2): 177-82.

16. Kassu A, Yabutani T, Mahmud ZH, Mohammad A, Nguyen N, Hailemariam G et al. Alterations in serum levels of trace elements in tuberculosis and HIV infections. Eur J Clin Nutr. 2006:60(5):580-6.

17. Amrutha SI, Sidesh BS, Khanrunissa SN. Nutritional status of TB cases registered under TB unit of Gulbarga city, India. Int J Bioassys. 2013;02(03):616-9. 
18. Dodor EA. Evaluation of nutritional status of new tuberculosis patients at the Effia-Nkwanta Regional Hospital, Sekondi, Ghana. Ghana Med J. 2008; 41(1):22-8.

19. Shah S, Whalen C, Kotler DP, Mayanja H, Namale A, Melikian G, et al. Severity of human immunodeficiency virus infection is associated with decreased phase angle, fat mass and body cell mass in adults with pulmonary tuberculosis infection in Uganda. J Nutr. 2001;131(11):2843-7.

20. Paton NI, Chua YK, Earnest A, Chee CB. Randomized controlled trial of nutritional supplementation in patients with newly diagnosed tuberculosis and wasting. Am J Clin Nutr. 2004;80(2):460-5.

Submit your next manuscript to BioMed Central and we will help you at every step:

- We accept pre-submission inquiries

- Our selector tool helps you to find the most relevant journal

- We provide round the clock customer support

- Convenient online submission

- Thorough peer review

- Inclusion in PubMed and all major indexing services

- Maximum visibility for your research

Submit your manuscript at www.biomedcentral.com/submit 